Paper No. 49

\title{
Modeling Step-Strain Relaxation and Cyclic Deformations of Elastomers
}

\author{
by \\ A. R. Johnson, ${ }^{1}$ T. Chen, and J. L. Mead ${ }^{2}$ \\ Army Research Laboratory, MS 240 \\ Analytical and Computational Methods Branch \\ NASA Langley Research Center \\ Hampton, VA 23681-0001
}

Presented at a meeting of the

Rubber Division, American Chemical Society

Cincinnati, Ohio

October $17-20,2000$

\footnotetext{
${ }^{1}$ Speaker.

${ }^{2}$ Department of Plastics Engineering, UMASS Lowell, Lowell, MA.
} 


\begin{abstract}
Data for step-strain relaxation and cyclic compressive deformations of highly viscous short elastomer cylinders are modeled using a large strain rubber viscoelastic constitutive theory with a rate-independent friction stress term added. In the tests, both small and large amplitude cyclic compressive strains, in the range of $1 \%$ to $10 \%$, were superimposed on steady state compressed strains, in the range of $5 \%$ to $20 \%$, for frequencies of 1 and $10 \mathrm{~Hz}$. The elastomer cylinders were conditioned prior to each test to soften them. The constants in the viscoelastic-friction constitutive theory are determined by employing a nonlinear least-squares method to fit the analytical stresses for a Maxwell model, which includes friction, to measured relaxation stresses obtained from a $20 \%$ step-strain compression test. The simulation of the relaxation data with the nonlinear model is successful at compressive strains of $5 \%, 10 \%, 15 \%$, and $20 \%$. Simulations of hysteresis stresses for enforced cyclic compressive strains of $20 \% \pm 5 \%$ are made with the model calibrated by the relaxation data. The predicted hysteresis stresses are lower than the measured stresses.
\end{abstract}

\title{
Introduction
}

It is generally known that modeling both relaxation and cyclic deformations of elastomers with a single constitutive theory is difficult. Simply stated, the physics at the molecular level can not be simulated with the simple continuum mechanics models used by design engineers. Elastomer components are often designed with multiple loading requirements. Thus, improved material models, that do not need to be tuned to each application, are needed for use in the finite element codes used by designers.

A number of methods that model viscoelastic stresses in elastomers are described in books. ${ }^{1,2}$ The mathematical form of the viscoelastic material models are often constructed by analogy to spring and dash-pot systems. The stress-strain constitutive form of these models can be written in either a history integral form or in an internal variable form. ${ }^{3}$ Each formulation has its acclaimed advantages, numerical strategies, etc. $^{4-11}$ Recently, engineers designing lead-lag elastomeric dampers employed in helicopter rotor dynamics ${ }^{12,13}$ have needed constitutive models valid for a wide range of frequencies and strains. Lesieutre and $\mathrm{Smith}^{13}$ have introduced rate independent friction in their one-dimensional models (valid in the frequency range from 0.01 to $10.0 \mathrm{~Hz}$.) Their model produced excellent frequency dependent storage and loss moduli data.

The purpose of this paper is to investigate the modeling of both relaxation and cyclic deformations with a single constitutive model, and to introduce a friction model which is described in terms of the tools used to model rubber elasticity. In this paper we: (a) Briefly review a large strain internal variable model for viscoelasticity, (b) Introduce a friction model and present its analytical form for tension-compression; (c) Describe the relaxation and cyclic tests conducted on short cylinders made of a viscous filled elastomer; (d) Perform a nonlinear least-squares analysis ${ }^{14}$ to fit the constitutive theory to 
relaxation data; and (e) Employ the constitutive theory to simulate cyclic tests at $20 \%$ compressive strain.

\section{Linear Viscoelasticity and Viscohyperelasticity}

This section contains a short review of internal variable formulations for linear viscoelasticity $^{1,2,3}$ and for viscohyperelasticity. ${ }^{6-9}$ They are presented in the onedimensional form employed throughout the remainder of this paper. The Maxwell solid is the linear viscoelastic model used in this study. A Maxwell solid is shown in Figure 1. At any time, $t$, the stress in the Maxwell solid is given by

$$
\sigma(t)=E_{e} \varepsilon(t)+\sum_{i=1}^{N} E_{i} \varepsilon_{i}(t)=\sigma_{e}(t)+\sum_{i=1}^{N} \sigma_{i}(t)
$$

where $\mathrm{N}$ is the number of internal solids, $E_{e}, \varepsilon(t)$ are the modulus and strain for the elastic solid, $E_{i}, \varepsilon_{i}(t)$ are the moduli and strains for the internal viscous solids, and $\sigma_{e}$, $\sigma_{i}$ are the corresponding stresses. During a time dependent deformation of this linear system the values of the internal strains are determined by integrating the differential equations that represent equilibrium of the spring and dash-pot system. The equations are

$$
\eta_{i} \frac{d\left(\varepsilon-\varepsilon_{i}\right)}{d t}=E_{i} \varepsilon_{i} \Rightarrow \eta_{i} \frac{d \varepsilon_{i}}{d t}+E_{i} \varepsilon_{i}=\eta_{i} \frac{d \varepsilon}{d t}
$$

where the $\eta_{i}$ are constants which are commonly determined from relaxation tests. When a time dependent stress is applied, Equations (1) and (2) are simultaneously integrated. If a time dependent strain is applied, Equation (2) is integrated and Equation (1) determines the stress.

The tools utilized to model the nonlinear elastic deformations of elastomers can be employed to model viscoelastic deformations. . $^{40}$ The method used here was termed viscohyprelasticity by Johnson and Quigley ${ }^{6}$ since it employs hyperelastic solids with time dependent reference shapes. A schematic of a viscohyperelastic solid is shown in Figure 2. The total value of the principal Cauchy stress shown in Figure 2 is expressed as follows

$$
\tau=\tau_{e}+\sum_{i=1}^{N} \tau_{i}
$$

where $\tau_{e}$ and $\tau_{i}$ are the Cauchy stresses for the elastic, $e$, and internal, $i$, solids respectively. In Figure 2 , the $L_{j i}$ represent time dependent reference lengths for side $j$ of internal solid $i$. The linear Maxwell model has a distribution of energies, $E_{i} \varepsilon_{i}^{2} / 2$, 
associated with the internal solids. Similarly, a viscohyperelastic solid has a distribution of energy density functions, $W_{i}$. During a step-strain deformation of a viscohyperelastic solid, the time dependent reference lengths of the internal solids change in time so that the resulting stresses represent the relaxation stresses. In previous efforts the evolution of the reference lengths (shapes for three-dimensional solids) was determined by relaxing ad-hoc stresses, which act on the reference shapes. In this effort the evolution of the reference lengths of the internal solids is determined by relaxing the viscous Cauchy stresses which act on the deformed solid. With the Cauchy-relaxation equation, the viscohyperelasticity formulation is a nonlinear form of the Maxwell solid formulation that is described with the tools employed for rubber elasticity. It is formulated for tension-compression as follows.

The stretches for the solids are shown in Figure 3. The elastic Cauchy stress, $\tau_{e}$, acting on the solid is given by ${ }^{15}$

$$
\tau_{e}=2\left(\lambda_{1}^{2}-\frac{1}{\lambda_{1}}\right)\left(\frac{\partial W_{e}}{\partial I_{1 e}}+\frac{1}{\lambda_{1}} \frac{\partial W_{e}}{\partial I_{2 e}}\right)
$$

where $I_{1 e}$ and $I_{2 e}$ are the strain invariants. ${ }^{15}$ Similarly, the viscous Cauchy stresses, $\tau_{i}$, on the solid are given by

$$
\tau_{i}=2\left(\lambda_{1 i}^{2}-\frac{1}{\lambda_{1 i}}\right)\left(\frac{\partial W_{i}}{\partial I_{1 i}}+\frac{1}{\lambda_{1 i}} \frac{\partial W_{i}}{\partial I_{2 i}}\right)
$$

where the stretches for the internal solids are given by $\lambda_{1 i}=\frac{\lambda_{1}}{L_{1 i}}$. The relaxation equations are linear differential equations in terms of stress, and are expressed as

$$
-\left.\frac{\eta_{i}}{E_{i}} \frac{d \tau_{i}}{d t}\right|_{\lambda_{1}}=\tau_{i} \quad i=1,2, \ldots, N
$$

Equation (6) is analogous to the relaxation equation for the spring dash-pot elements in a Maxwell solid, $-\frac{\eta_{i}}{E_{i}} \frac{d \sigma_{i}}{d t}=\sigma_{i}$, where $\sigma_{i}$ is the nominal stress. Expanding Equation (6) results in the following nonlinear differential equation for $L_{1 i}(t)$,

$$
\frac{d L_{1 i}}{d t}=\frac{L_{1 i}}{\eta_{i} \lambda_{1 i}} \frac{E_{i} \tau_{i}}{\left(G_{1 i}+G_{2 i}\right)}
$$

where $G_{1 i}=2\left(2 \lambda_{1 i}+\frac{1}{\lambda_{1 i}^{2}}\right)\left(\frac{\partial W_{i}}{\partial I_{1 i}}+\frac{1}{\lambda_{1 i}} \frac{\partial W_{i}}{\partial I_{2 i}}\right)-\frac{2}{\lambda_{1 i}^{2}}\left(\lambda_{1 i}^{2}-\frac{1}{\lambda_{1 i}}\right) \frac{\partial W_{i}}{\partial I_{2 i}}$ 
and $\quad G_{2 i}=\frac{4}{\lambda_{1 i}}\left(\lambda_{1 i}^{2}-\frac{1}{\lambda_{1 i}}\right)^{2}\left(\frac{\partial^{2} W_{i}}{\partial I_{1 i}^{2}}+\frac{2}{\lambda_{1 i}} \frac{\partial^{2} W_{i}}{\partial I_{1 i} \partial I_{2 i}}+\frac{1}{\lambda_{1 i}^{2}} \frac{\partial^{2} W_{i}}{\partial I_{2 i}^{2}}\right)$

Equations (3) and (7) are simultaneously integrated if a time dependent stress is applied, and Equation (7) is integrated alone if a time dependent stretch is specified. The authors note, the purpose of viscohyperelasticity, and other related nonlinear viscoelasticity theories, is not to simulate one-dimensional problems, but to provide methods for the modeling of three-dimensional problems in which the viscous component of stress depends differently on the stretches than the elastic components do.

\section{Friction Model}

One-dimensional models, like the Maxwell solid shown in Figure 1, can be modified with elements that add rate independent friction-like effects. Recently, "friction-elastic" elements were added to a Maxwell solid ${ }^{13}$ to improve the prediction of the storage and loss moduli as a function of frequency for a dynamically loaded elastomeric helicopter lead-lag damper. The model was very successful. The success obtained by adding rate independent friction-elastic stresses in the one-dimensional model suggests that threedimensional friction-like models should be investigated. Below we describe a friction model for elastomers subjected to tension and compression deformations.

As the deformed solid undergoes a virtual displacement, friction stresses will resist the deformation in each principal direction. With $\tau_{F i}$ as the friction stress in the direction of the stretch $\lambda_{i}$, the work done, $\delta Q$, during a virtual displacement for an incompressible solid is

$$
\delta Q=\sum_{j=1}^{3} \frac{\left|\tau_{F j}\right|}{\lambda_{j}}\left|\delta \lambda_{j}\right|
$$

where the absolute values have been used to avoid adding extra vector notation (the friction stress is always in the opposite direction to that of the virtual displacement.) For three-dimensional deformations, Equation (8) can be introduced into the variational formulation for the viscoelastic deformation of the solid.

Specific forms of $\tau_{F i}$ need to be investigated. The approach taken here is to employ a friction stress that is small near the reference state and is large at very large values of the stretches. According to the arithmetic-geometric-mean inequality, the surface area of a deformed incompressible unit cube is minimal in its undeformed configuration. ${ }^{16}$ Friction stresses that are proportional to the total deformed cube's area are thus minimal in the undeformed configuration. This suggests that an 'area rule' formula for the friction stress may be useful. Here, the friction stress, $\tau_{F i}$, is assumed proportional to the surface 
areas of the deformed unit cube, which are parallel to the direction of the principal stretch $\lambda_{i}$. This form of the friction stress is proportional to only part of the unit cube's area so the friction stress is not minimal in the reference state. However, the friction stress is minimal near the reference state and the simplicity of its analytical form is attractive. The friction stresses are given by

$$
\left|\tau_{F i}\right|=C^{F} \lambda_{i}\left(\lambda_{j}+\lambda_{k}\right) \quad i \neq j \neq k
$$

The coefficient $C^{F}$ is determined by a least-squares fit to measured data. The stretches in the solid are related by

$$
\lambda_{2}=\lambda_{3}=\frac{1}{\sqrt{\lambda_{1}}}
$$

and $\frac{\left|\delta \lambda_{2}\right|}{\lambda_{2}}=\frac{\left|\delta \lambda_{3}\right|}{\lambda_{3}}=\frac{1}{2} \frac{\left|\delta \lambda_{1}\right|}{\lambda_{1}}$

The virtual work becomes

$$
\delta Q=\left(\left|\tau_{F 1}\right|+\left|\tau_{F 2}\right|\right) \frac{\left|\delta \lambda_{1}\right|}{\lambda_{1}}
$$

The Cauchy stress, in the direction of $\lambda_{1}$, needed to overcome this resistance is

$$
\tau_{1}^{F}=\left(\left|\tau_{F 1}\right|+\left|\tau_{F 2}\right|\right) \frac{\dot{\lambda}_{1}}{\left|\dot{\lambda}_{1}\right|}
$$

where $\dot{\lambda}_{1}=\frac{d \lambda_{1}}{d t}$, and the direction of the stress as a function of the strain rate is provided by $\frac{\dot{\lambda}_{1}}{\left|\dot{\lambda}_{1}\right|}$. For the case of tension and compression, Equations (9) and (10) are combined and result in

$$
\tau_{1}^{F}=C^{F}\left(3 \sqrt{\lambda_{1}}+\frac{1}{\lambda_{1}}\right) \frac{\dot{\lambda}_{1}}{\left|\dot{\lambda}_{1}\right|}
$$

The friction stress, $\tau_{1}^{F}$, is minimal at $\lambda_{1}=0.816$ and grows without bound when $\lambda_{1} \rightarrow 0$ and when $\lambda_{1} \rightarrow \infty$. The friction stress given by Equation (14) is added to the sum of the elastic and viscous stresses to obtain the total stress. 


\section{Experimental}

Compression tests were performed on cylindrical specimens using an Instron model 1331 servohydraulic testing machine. The specimens were conditioned before each series of tests by cycling the sample to a $30 \%$ compressive strain at $0.5 \mathrm{~Hz}$ for 20 cycles. The specimen was unloaded and allowed to relax for 15 minutes before the next test, and between each test. After conditioning and relaxing the cylinders, the cylinders had a diameter of $2.87 \mathrm{~cm}$ and a height of $1.19 \mathrm{~cm}$, see Figure 4 . Compression relaxation data were obtained by compressing the specimen at a crosshead rate of $610 \mathrm{~cm} / \mathrm{min}$ to a specified strain, then holding at that displacement for 15 minutes while recording the load. At the start of the test, the test machine piston was offset from the zero load position to allow the piston time to come up to the correct speed before applying the load to the specimen. Four different compressive strain levels were used to obtain relaxation data: $5,10,15$ and $20 \%$.

Ramp to cyclic (enforced strain) tests were performed by compressing the sample to a specified mean strain level then applying different sinusoidal amplitudes about the mean strain level. The tests were performed at a ramp speed of $0.36 \mathrm{~cm} / \mathrm{min}$ and two different frequencies: $1 \mathrm{~Hz}$ and $10 \mathrm{~Hz}$. The samples were conditioned before testing using the procedure described above. Between each test the sample was allowed to rest for 15 minutes. The matrix for the cyclic tests is described in Table I. All of the measured hysteresis loops are shown in Figures 5 and 6.

Table I. Cyclic Testing Matrix

\begin{tabular}{|c|c|}
\hline Mean Strain Level & Strain Amplitude \\
\hline $5 \%$ & $1 \%$ \\
\hline $5 \%$ & $2.5 \%$ \\
\hline $10 \%$ & $2.5 \%$ \\
\hline $10 \%$ & $5 \%$ \\
\hline $15 \%$ & $5 \%$ \\
\hline $15 \%$ & $10 \%$ \\
\hline $20 \%$ & $5 \%$ \\
\hline $20 \%$ & $10 \%$ \\
\hline
\end{tabular}

\section{Nonlinear Least Square Fit to Data}

It is difficult to directly determine all of the parameters in the nonlinear viscoelasticfriction model described above from time dependent stress-strain data. The following procedure, which employs the linear Maxwell model with friction, was applied to determine values for the parameters $\left(\eta_{i} / E_{i}\right.$ in Equation (6)) which allow the relaxation data to be simulated. Equations (1) and (2) can be combined so that Equation (1) can be written in history integral form. When the friction stress, in nominal stress form, is added to the history integral form of the viscoelastic stress, the total stress becomes 


$$
\sigma(t)=E_{e} \varepsilon(t)+\int_{\xi=0}^{t} \sum_{i=1}^{N} E_{i} e^{\frac{-(t-\xi) E_{i}}{\eta_{i}}} \frac{d \varepsilon(\xi)}{d \xi} d \xi+C^{F}\left(\frac{3}{\sqrt{1+\varepsilon(t)}}+\frac{1}{(1+\varepsilon(t))^{2}}\right) \frac{\dot{\varepsilon}}{|\dot{\varepsilon}|}
$$

where the relation $\lambda=1+\varepsilon$ was employed in the nominal stress form of Equation (14). If the enforced strain is expressed in polynomial form, Chen ${ }^{14}$ has developed a procedure that determines $E_{e}, E_{1}, \ldots, E_{N}, \eta_{1}, \ldots, \eta_{N}$ by performing a nonlinear least-squares fit of the first two terms of Equation (15) to the measured data. Chen's least-squares procedure was modified in this effort to include all the terms in Equation (15). The measured cross head displacement as a function of time (for the $20 \%$ compressive strain relaxation test) was converted to compressive strain as a function of time. The strain as a function of time was modeled with four polynomials which were entered into Equation (15). The required differentiation and integration was carried out and an analytical expression for the stress, $\sigma_{i}(t)$, was obtained. The nonlinear least-squares procedure was allowed to optimize the data fit with the elastic modulus, $E_{e}$, the friction term, $C^{F}$, and four internal solids, $E_{1}, \ldots, E_{4}, \eta_{1}, \ldots, \eta_{4}$. The parameters determined are shown in Table II. The least-squares fit of the Maxwell solid with friction to the data is presented in Figures 7 and 8. A stress jump due to the friction 'turning off' is also shown in Figure 8.

Table II. Results of Least-Squares Fit.

\begin{tabular}{|c|c|}
\hline $\begin{array}{c}\text { Elastic Moduli } \\
(\mathrm{MPa})\end{array}$ & $\begin{array}{c}\text { Time Constants } \\
(\mathrm{s})\end{array}$ \\
\hline$E_{1}=11.14$ & $\eta_{1} / E_{1}=0.01237$ \\
\hline$E_{2}=4.770$ & $\eta_{2} / E_{2}=0.3075$ \\
\hline$E_{3}=2.856$ & $\eta_{3} / E_{3}=5.942$ \\
\hline$E_{4}=2.850$ & $\eta_{4} / E_{4}=130.4$ \\
\hline$E_{E}=7.006$ & -- \\
\hline$C^{F}=0.007936$ & $-\cdots$ \\
\hline
\end{tabular}

The ratios $E_{1} / \eta_{1}, \ldots, E_{4} / \eta_{4}$ and the constant $C^{F}$ were directly used in the viscohyperelastic-friction model. To complete the model, neo-Hookean energy density functions were employed as follows

$$
W_{e}=C^{e}\left(I_{1}-3\right) \quad \text { and } \quad W_{i}=C^{i}\left(I_{1 i}-3\right)
$$

The relaxed nominal stress, $\sigma_{1}^{e}$, at $\mathrm{t}=900 \mathrm{~s}$ for a compressive stretch ratio of $\lambda_{1}=0.80$ was used with the nominal stress formula 


$$
\sigma_{1}^{e}=2 C^{e}\left(\lambda_{1}-\frac{1}{\lambda_{l}^{2}}\right)
$$

to compute $C^{e}=0.9377 \mathrm{MPa}$. The peak nominal stress, $4.5 \mathrm{MPa}$ in Figure 8 , and the nominal stress formula imply that $\sum_{i=1}^{4} C^{i} \geq 2.01 \mathrm{MPa}$. The constants $C^{i}$ were set in proportion to the constants $E_{i}$ and to sum to $2.01 \mathrm{MPa}$. Three numerical simulations of the ramp-relaxation tests were made in which the values for the $C^{i}$ were scaled to improve the predictions of the peak stress. The third set of numbers $\left(C^{1}=1.453 \mathrm{MPa}\right.$, $C^{2}=0.6221 \mathrm{MPa}$, and $C^{3}=C^{4}=0.3717 \mathrm{MPa}$ ) were selected. All four ramp-relaxation tests were then simulated with the viscohyperelastic-friction model. The results are shown in Figures 9 to 11 . Hysteresis loops computed for a cyclic frequency of $1.0 \mathrm{~Hz} \mathrm{at}$ stretch ratios of $0.80 \pm 0.05$ are shown in Figure 12. The inner loop represents the case without the friction stress. We note, the ramp-relaxation data was used to determine the constants for the model. The constant representing the friction term, $C^{F}$, is only involved during the ramp to strain part of the test (the time when the strain rate is nonzero.) This represents a very small portion of the data and a small value of $C^{F}$ is expected. If dynamic data is fit, instead of relaxation data, a larger value of $C^{F}$ may result.

\section{Simulations of Cyclic Compressive Loading}

The viscohyperelastic-friction model described above was employed to simulate the measured cyclic stress data. The results for a $20 \%$ compression with a harmonic oscillation of $5 \%$ are shown in Figures 13 and 14 for cyclic frequencies of 1.0 and 10.0 $\mathrm{Hz}$ respectively. Results for the Maxwell model are also included. Both the Maxwell and viscohyperelastic models under predict the measured hysteresis stresses. The slopes of the major axes of the measured hysteresis loops indicate a stiffer viscous resistance than is indicated by the linear and nonlinear models. Throughout the entire range of the data, the major axes of the measured hysteresis loops indicate a stiff viscoelastic resistance, see Figures 5 and 6.

\section{Conclusions}

Step-strain relaxation and cyclic compressive deformations of a highly viscous filled elastomer were modeled with Maxwell solid theory and with viscohyperelastic solid theory. Both models included a rate independent friction stress described by the principal stretch ratios. The Maxwell-friction model was directly calibrated from ramp-relaxation data by employing a nonlinear least-squares method. The relaxation rates, friction constant, and elastic energy function for the viscohyperelastic-friction model were taken 
from the Maxwell-friction model and the relaxed stress at $t=900 \mathrm{~s}$. The energy functions for the internal solids were determined by three numerical simulations of a ramp-relaxation test. The resulting viscohyperelastic-friction model is useful for simulating the relaxation data. Dynamic stress data, determined in the cyclic loading tests, was not simulated well. Future models, calibrated by relaxation data, should provide much larger dynamic viscous-friction stresses to be useful for designers. 


\section{References}

1. I. M. Ward, "Mechanical Properties of Solid Polymers," John Wiley \& Sons, New York, (1983).

2. J. E. Mark, B. Erman, and F. R. Eirich, "Science and Technology of Rubber", 2nd Ed., Academic Press, NY, (1994).

3. A. R. Johnson, Shock and Vibration Digest, 31, 91 (1999).

4. J. C. Simo, Comput. Methds. Appl. Mech. Eng., 60, 153 (1987).

5. A. R. Johnson and R. G. Stacer, Rubber Chem. Technol., 66, 567 (1993).

6. A. R. Johnson and C. J. Quigley, Rubber Chem. Technol., 65, 137 (1992).

7. A. R. Johnson, C. J. Quigley, D. G. Young, and J. A. Danik, Tire Sci. Technol., TSTCA, 21, 179 (1993).

8. A. R. Johnson, C. J. Quigley, and C. E. Freese, Comput. Methds. Appl. Mech. Eng., 127, 163 (1995).

9. A. R. Johnson, C. J. Quigley, and J. L. Mead, Rubber Chem. Technol., 67, 904 (1994).

10. C. J. Quigley, J. L. Mead, and A. R. Johnson, Rubber Chem. Technol., 68, 230 (1995).

11. S. Shaw, A. R. Johnson, and J. R. Whiteman, in "The Mathematics of Finite Elements and Applications X, MAFELAP 1999," J. R. Whiteman, Ed., Elsevier, NY, pp 63 to $85,(2000)$.

12. G. Hausmann, and P. Gergley, in "Proceedings of the 18th European Rotorcraft Forum," Avignon, France, pp 88-1 to 88-17, (1992).

13. C. R. Brackbill, G. A. Lesieutre, E. C. Smith, and L. E. Ruhl, J. American Helicopter. Soc., 45, No. 1, pp 34 to 42 (2000).

14. T. Chen, NASA/TM-2000-210123, (2000).

15. L. R. G. Treloar, "The Physics of Rubber Elasticity," Clarendon Press, ISBN $0198513550,(1975)$.

16. I. Fried and A. R. Johnson, Comput. Methds. Appl. Mech. Eng., 69, 53 (1988). 


\section{Figure Titles}

Figure 1. Linear Maxwell solid.

Figure 2. Viscohyperelastic solid.

Figure $3 . \quad$ Viscohyperelastic solid kinematics.

Figure 4. Cylindrical test specimen.

Figure 5. Measured cyclic compressive stress as a function of stretch ratio, for all tests at a frequency of $1.0 \mathrm{~Hz}$.

Figure 6. Measured cyclic compressive stress as a function of stretch ratio, for all tests at a frequency of $10.0 \mathrm{~Hz}$.

Figure 7. Stress relaxation data and least-squares fit to Maxwell model with friction $(0.0$ to $1.0 \mathrm{~s})$.

Figure 8. Stress relaxation data and least-squares fit to Maxwell model with friction (from 0.01 to $0.065 \mathrm{~s}$ ).

Figure 9. Measured and computed relaxation stresses for stretch ratios of $0.95,0.90$, 0.85 , and 0.80 (time: 0.0 to $0.1 \mathrm{~s}$ ).

Figure 10. Measured and computed relaxation stresses for stretch ratios of $0.95,0.90$, 0.85 , and 0.80 (time: 0.0 to $1.0 \mathrm{~s}$ ).

Figure 11. Measured and computed relaxation stresses for stretch ratios of $0.95,0.90$, 0.85 , and 0.80 (time: 0.0 to $30.0 \mathrm{~s}$ ).

Figure 12. Computed cyclic compressive stress as a function of stretch ratio $(0.80 \pm 0.05)$, frequency of $1.0 \mathrm{~Hz}$, with and without friction.

Figure 13. Measured and computed cyclic compressive stress as a function of stretch ratio $(0.80 \pm 0.05)$, frequency of $1.0 \mathrm{~Hz}$.

Figure 14. Measured and computed cyclic compressive stress as a function of stretch ratio $(0.80 \pm 0.05)$, frequency of $10.0 \mathrm{~Hz}$. 


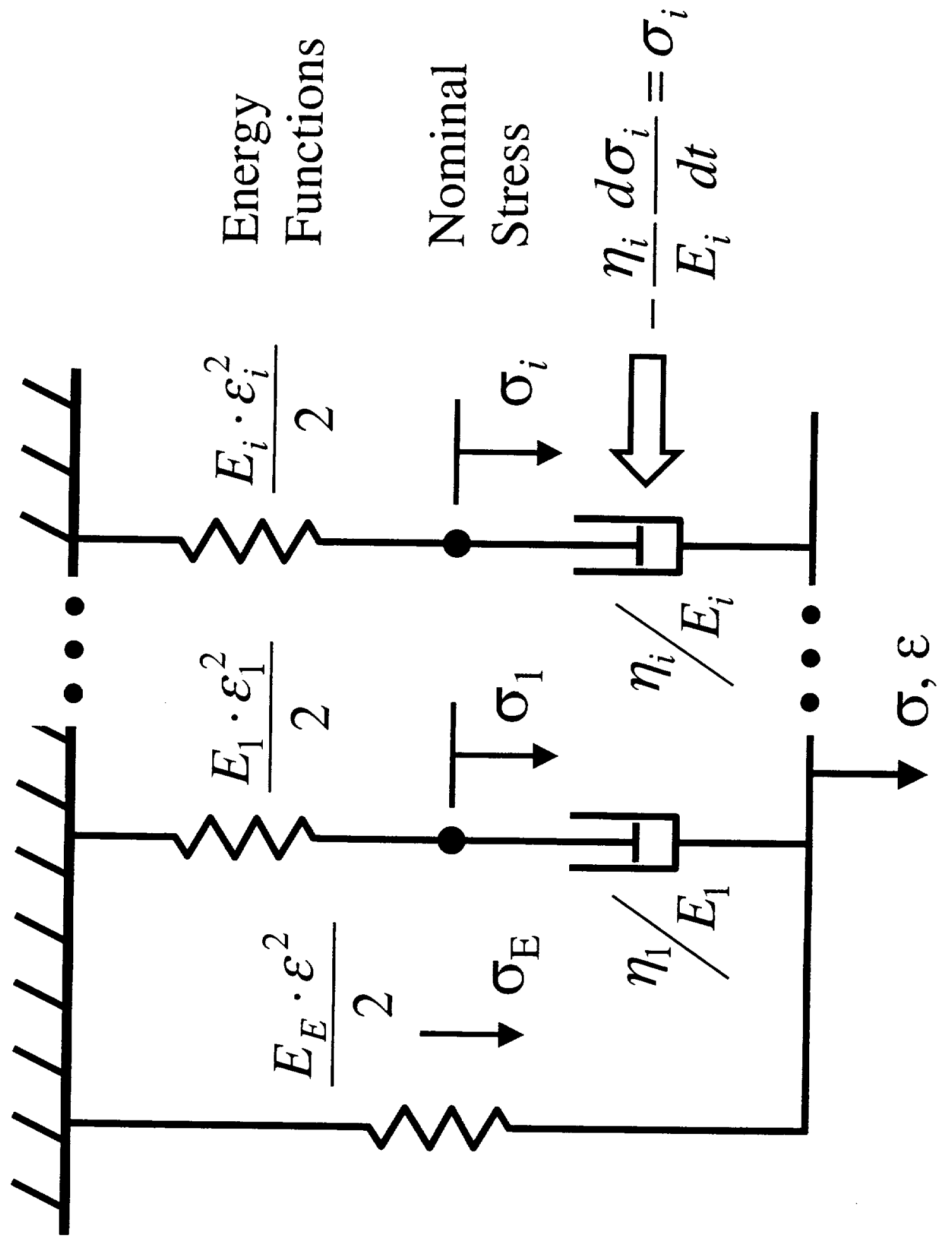




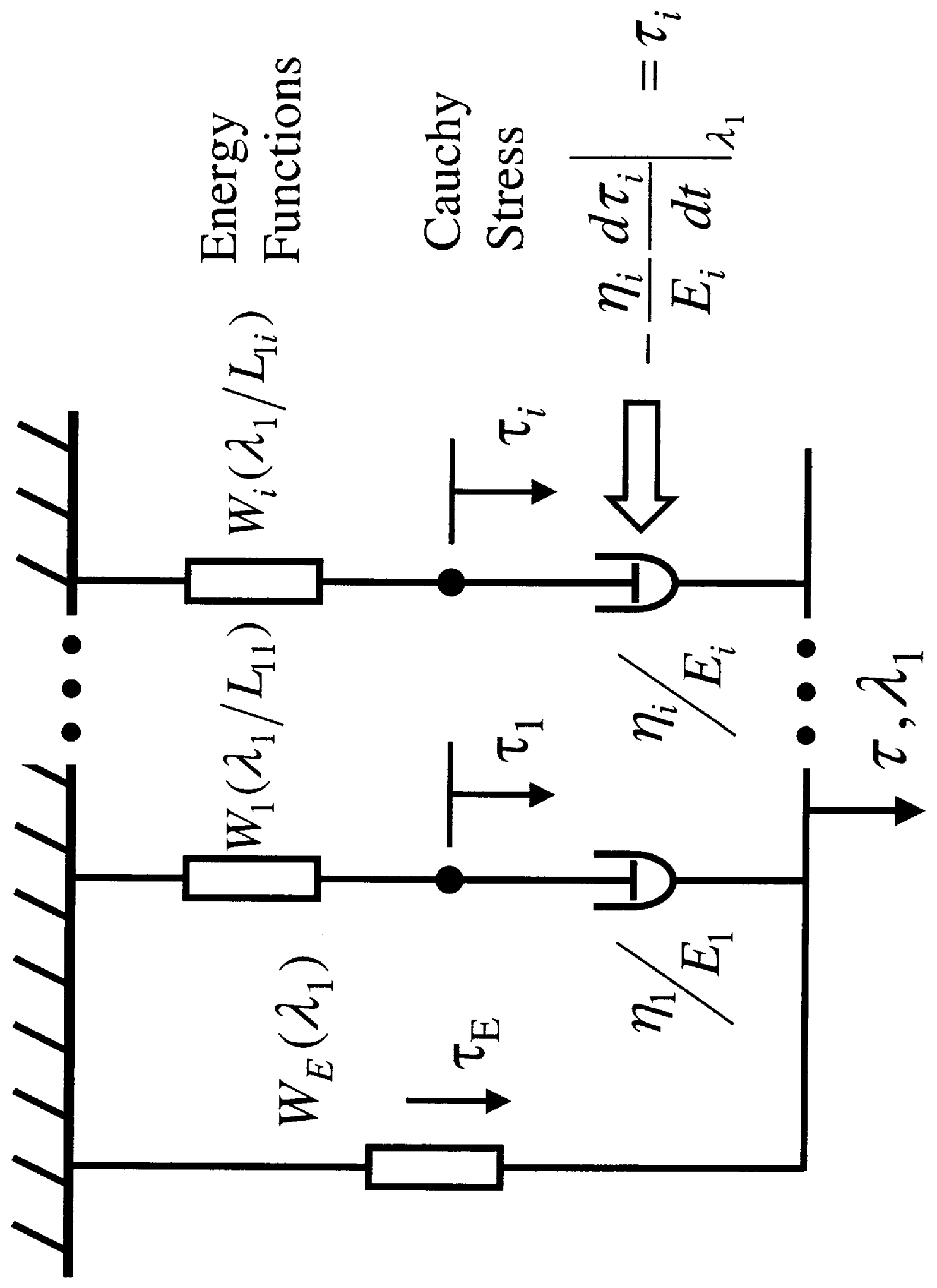




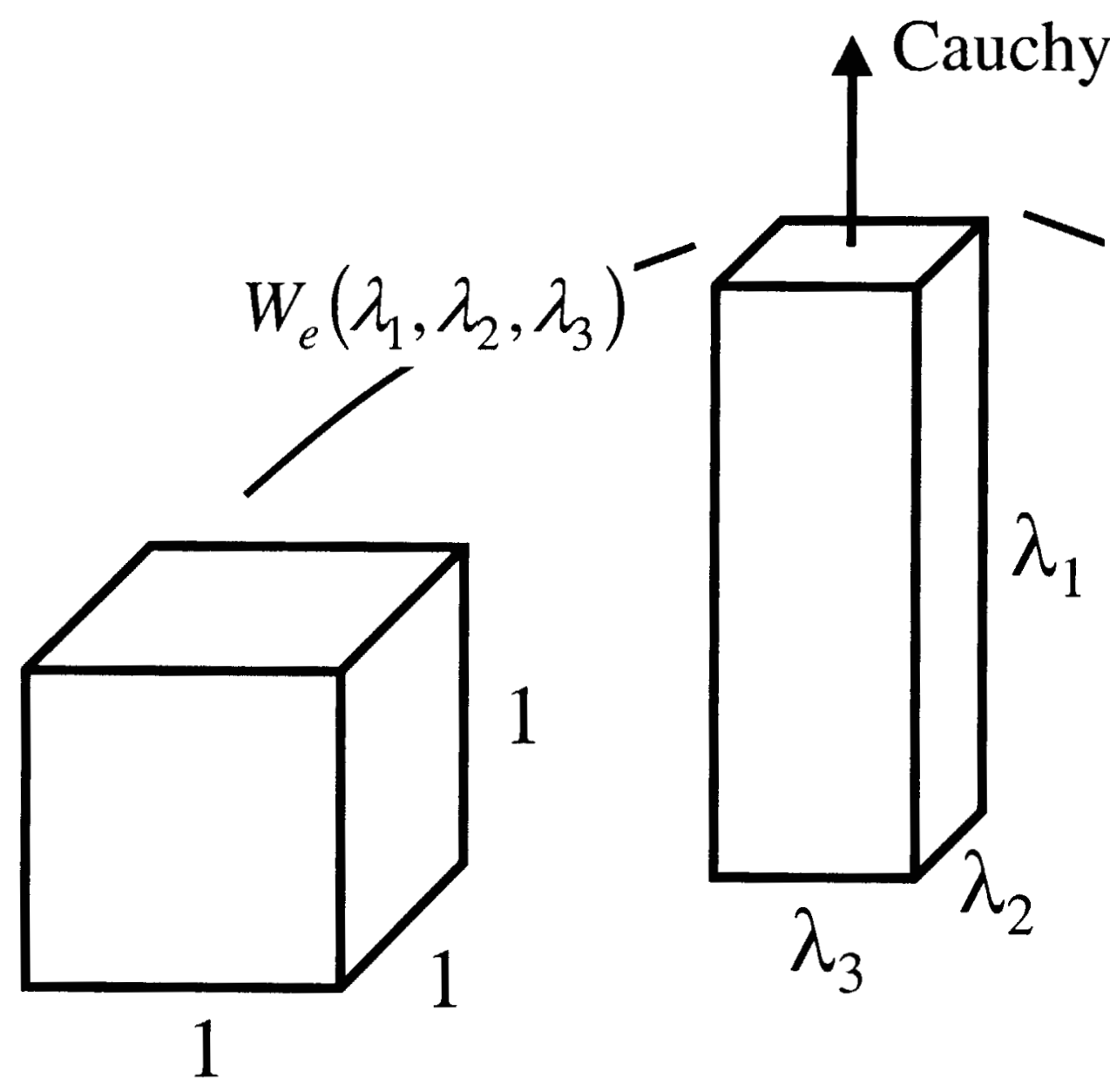

Reference shape for elastic solid
Deformed solid's shape

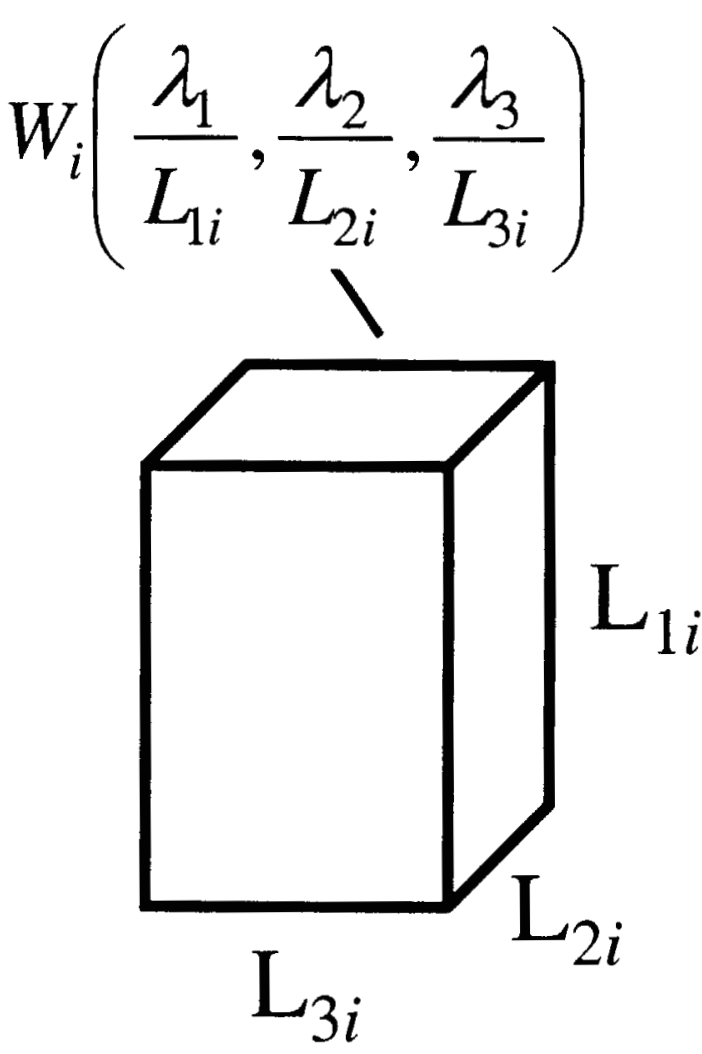

Reference shape for internal solid $(i)$ 


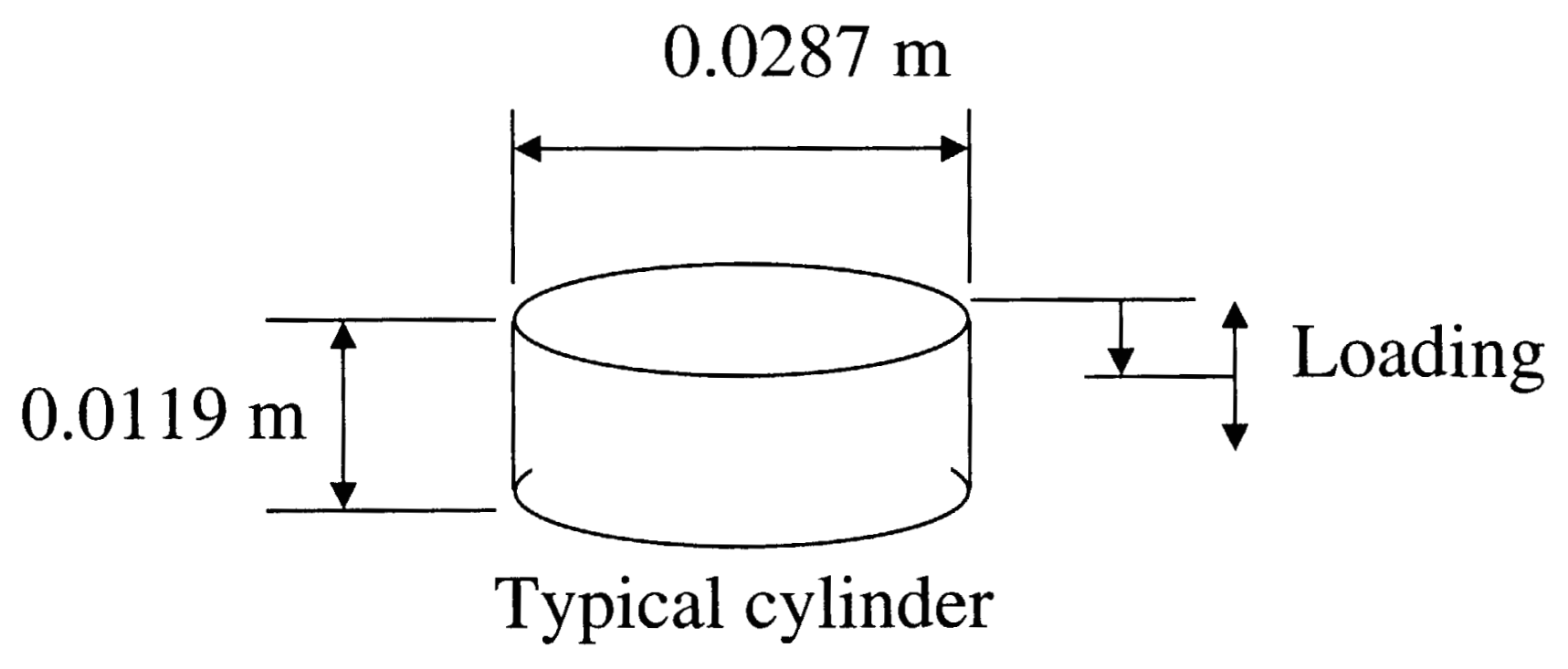

Conditioned $5-30 \%$ at $0.5 \mathrm{~Hz}$ for 20 cycles, relax for $15 \mathrm{~min}$, then test. 


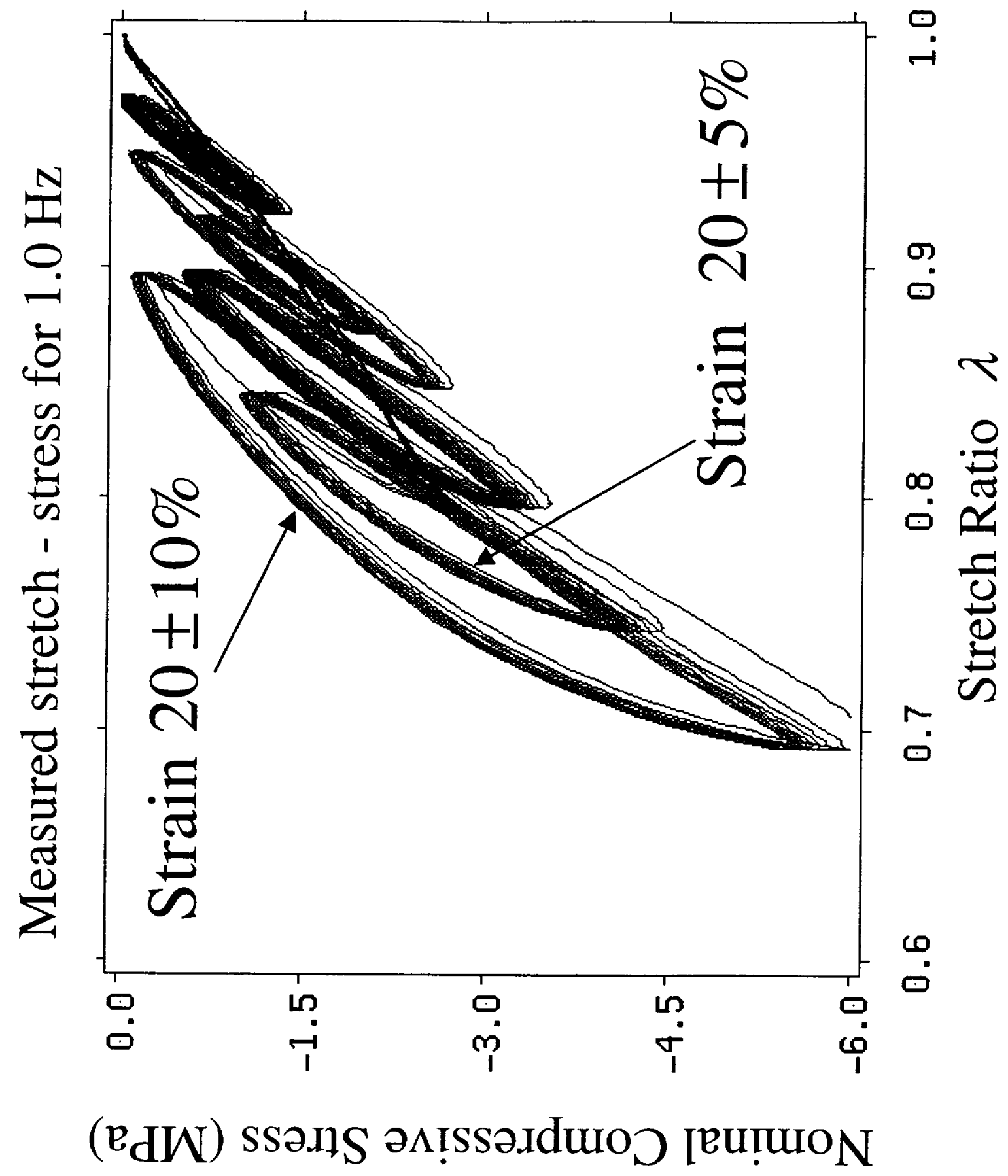




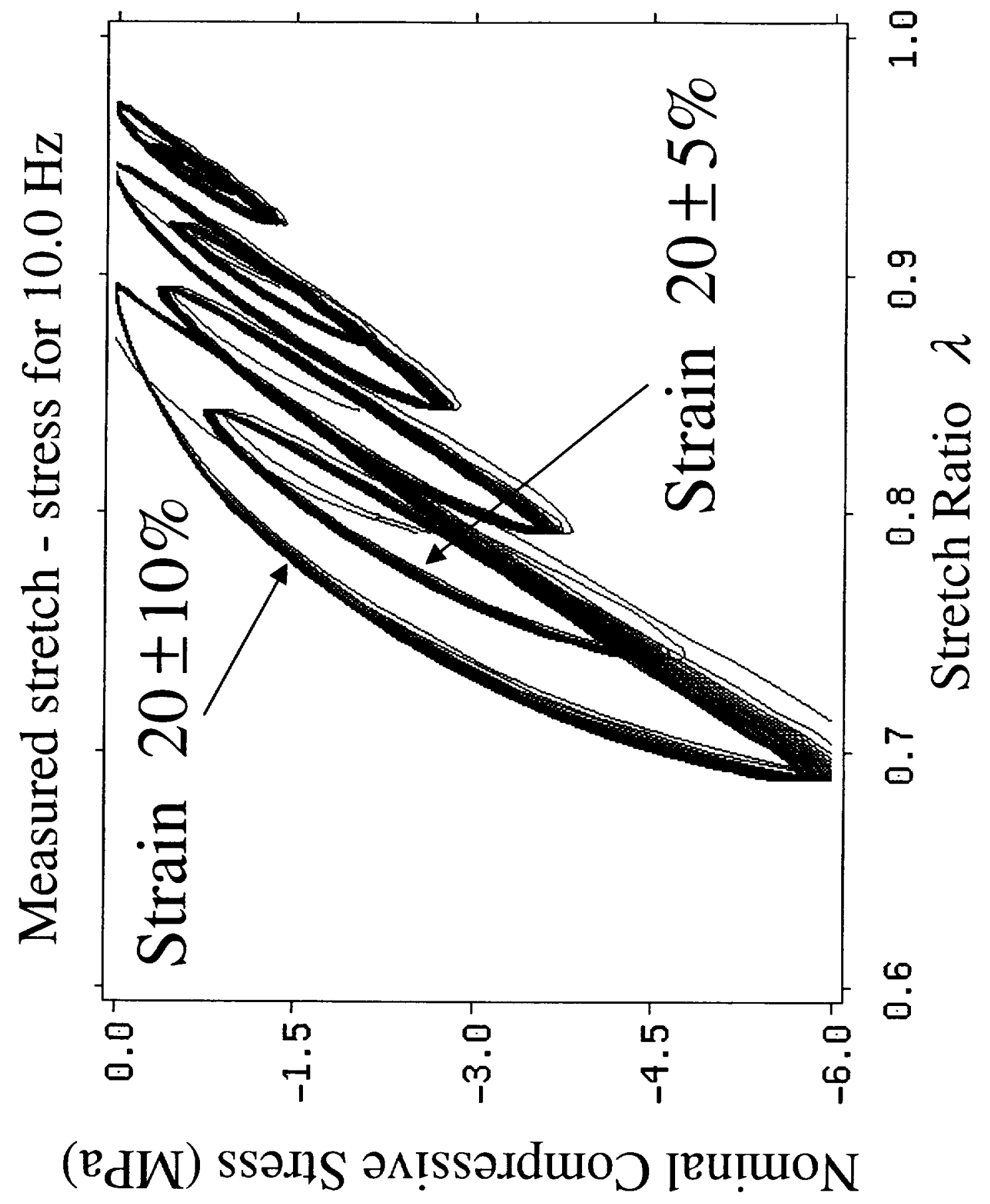




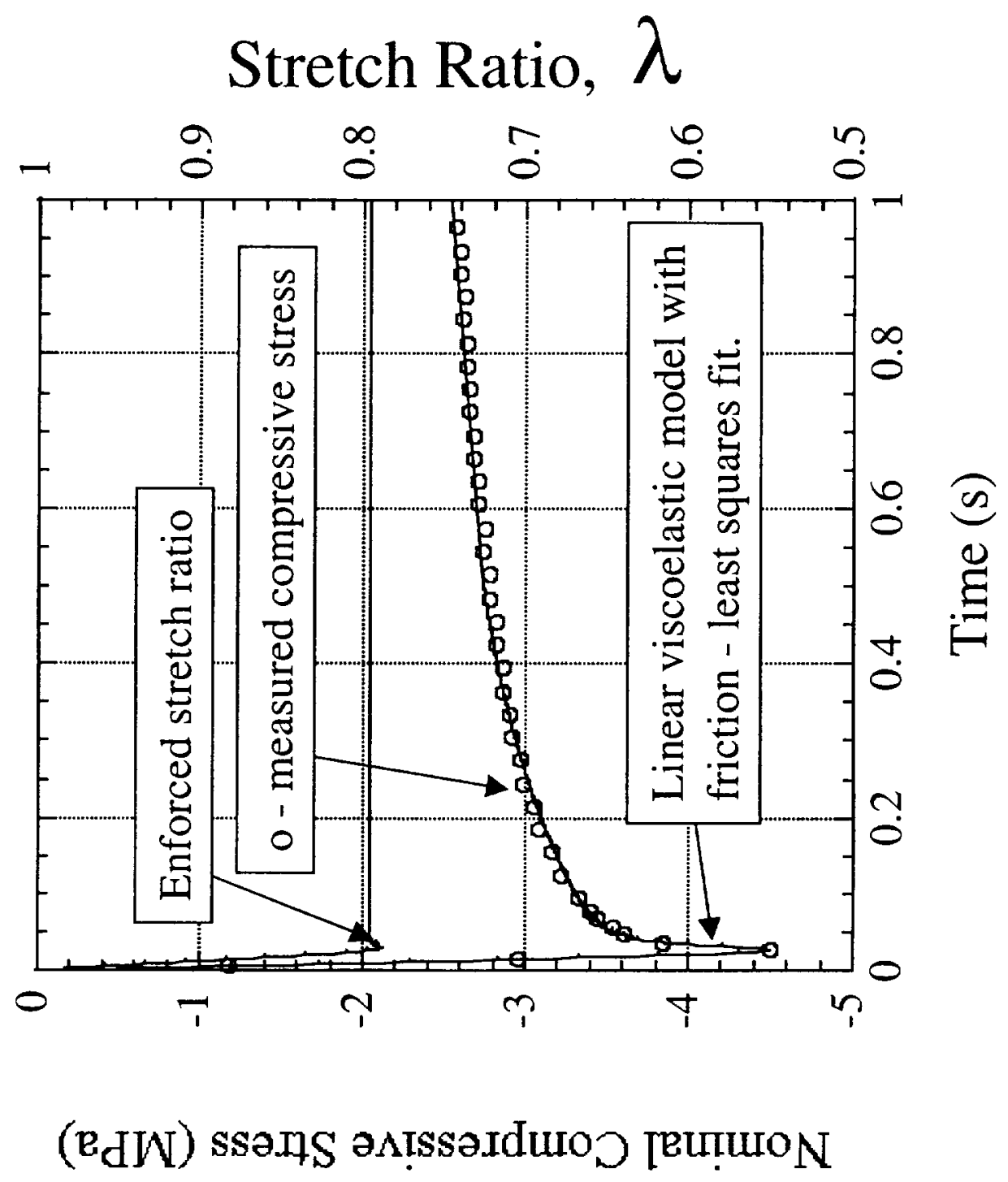




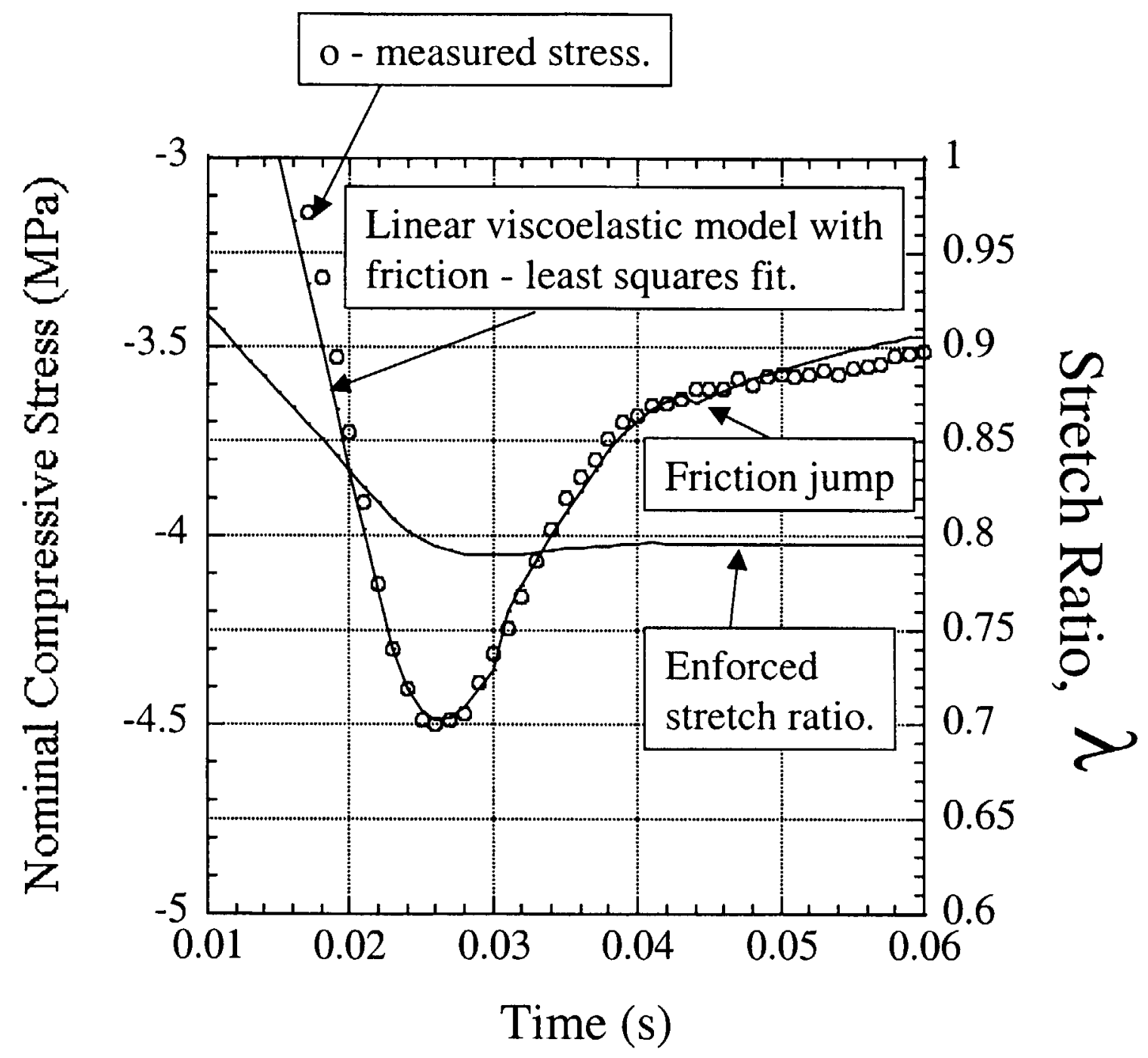




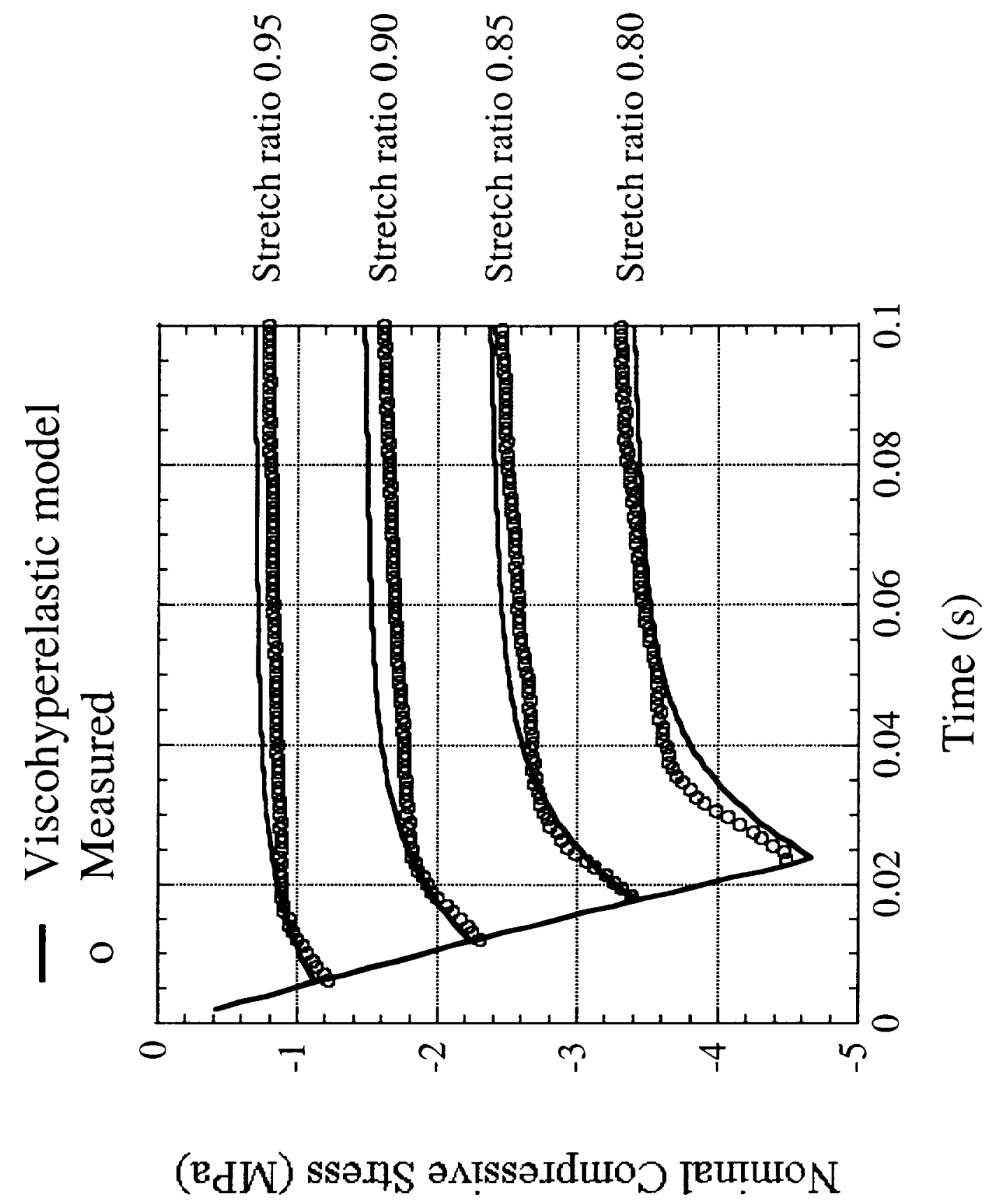




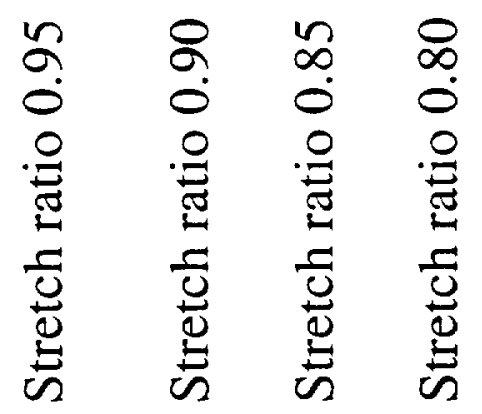

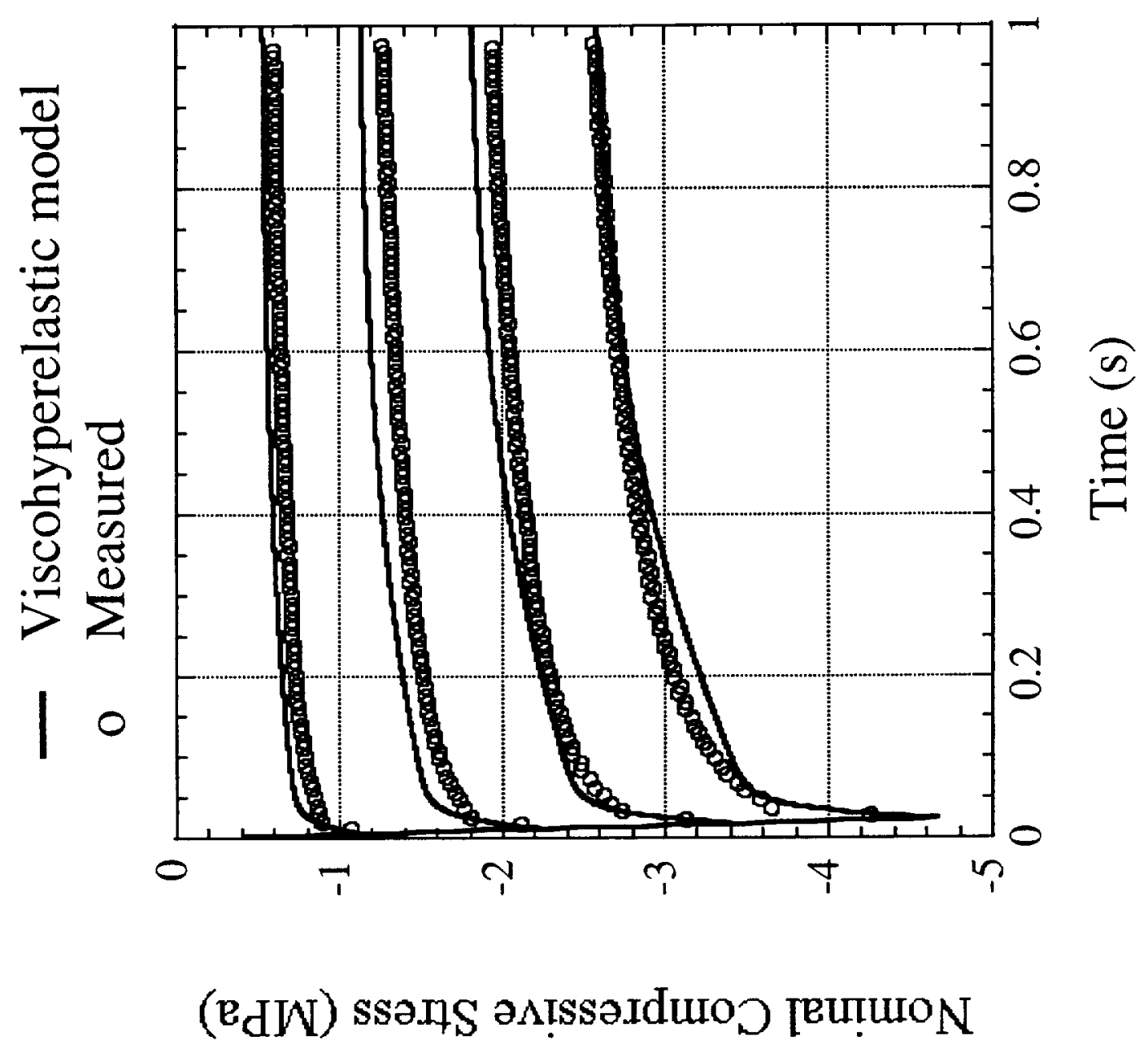




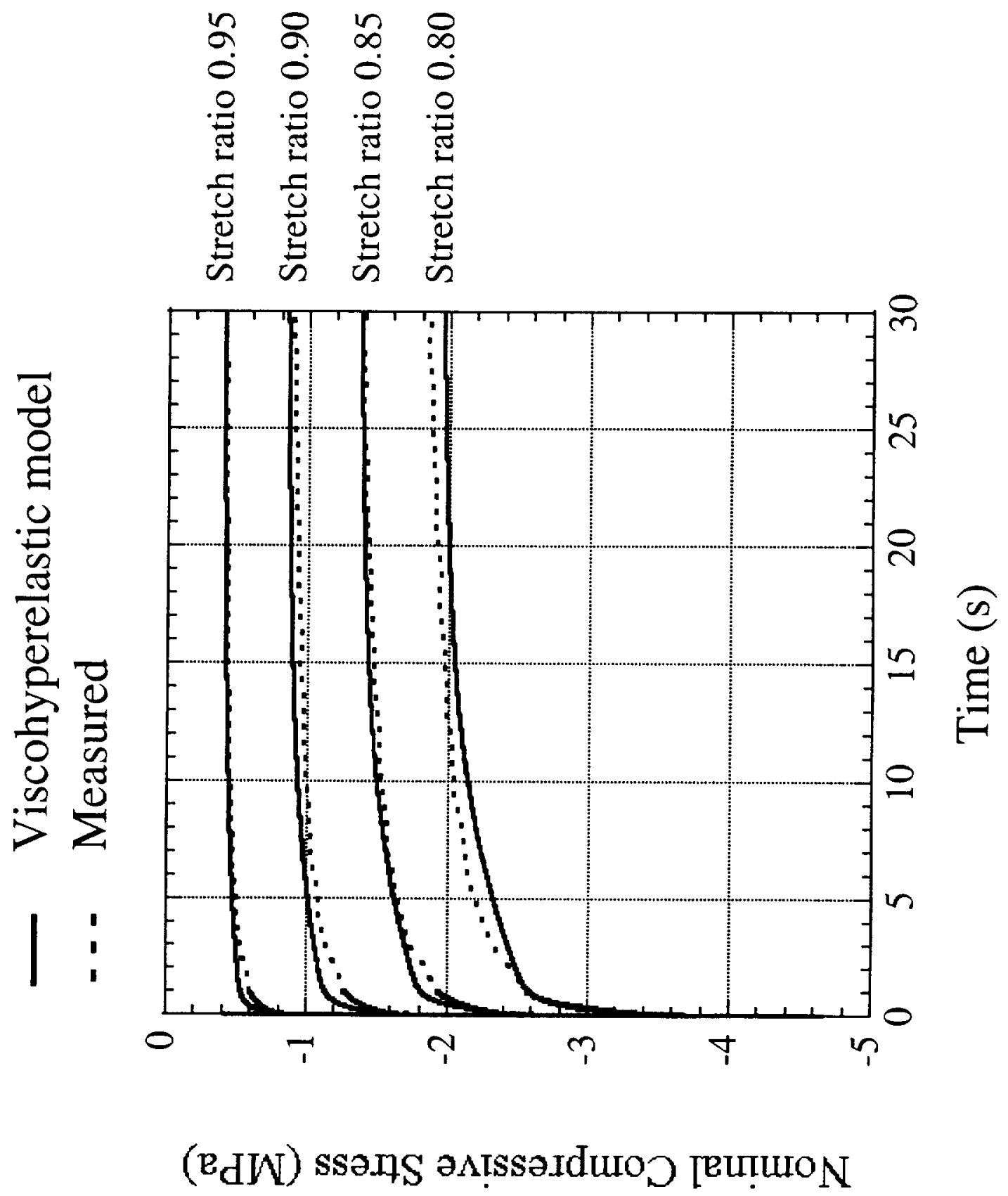




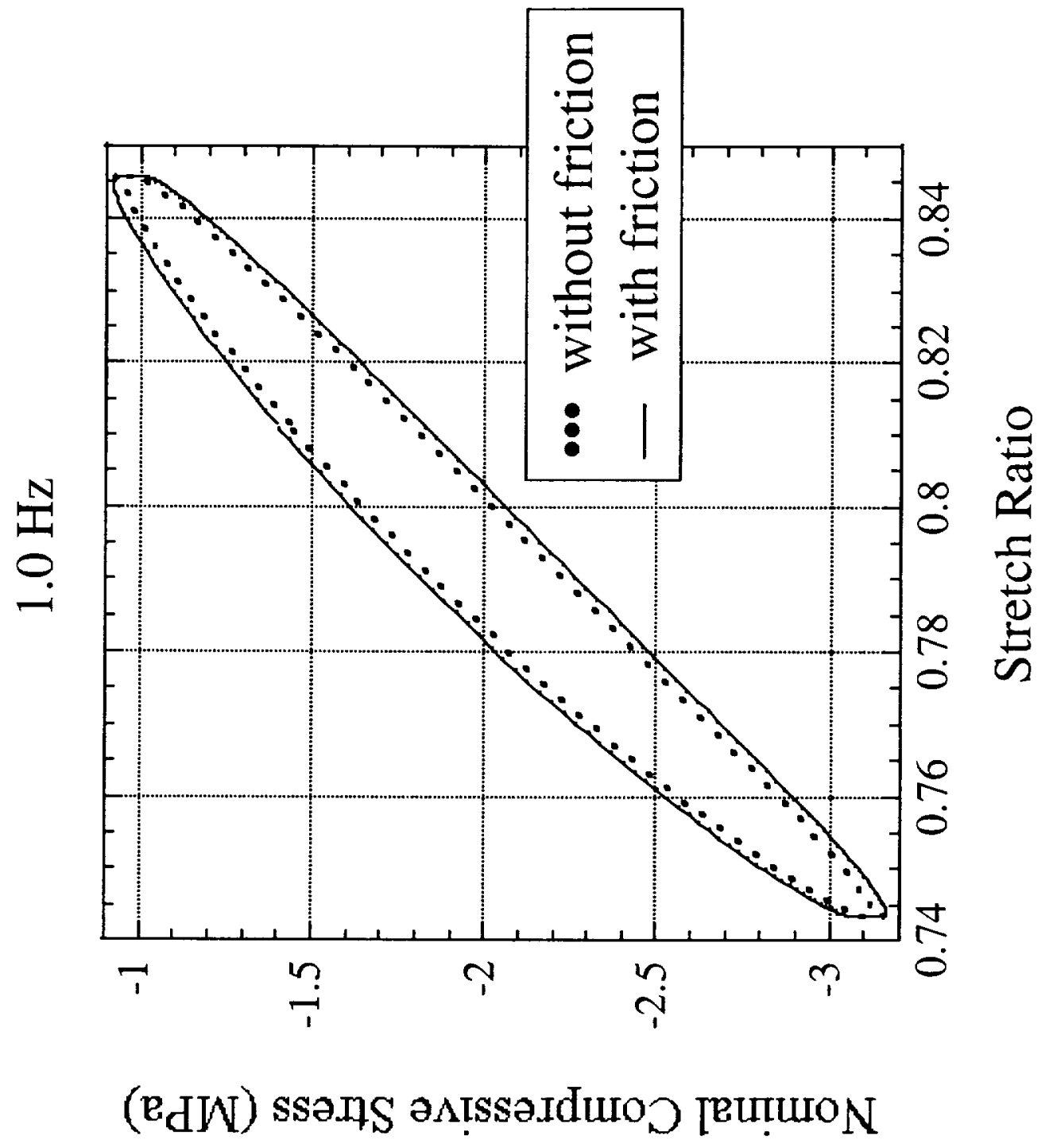




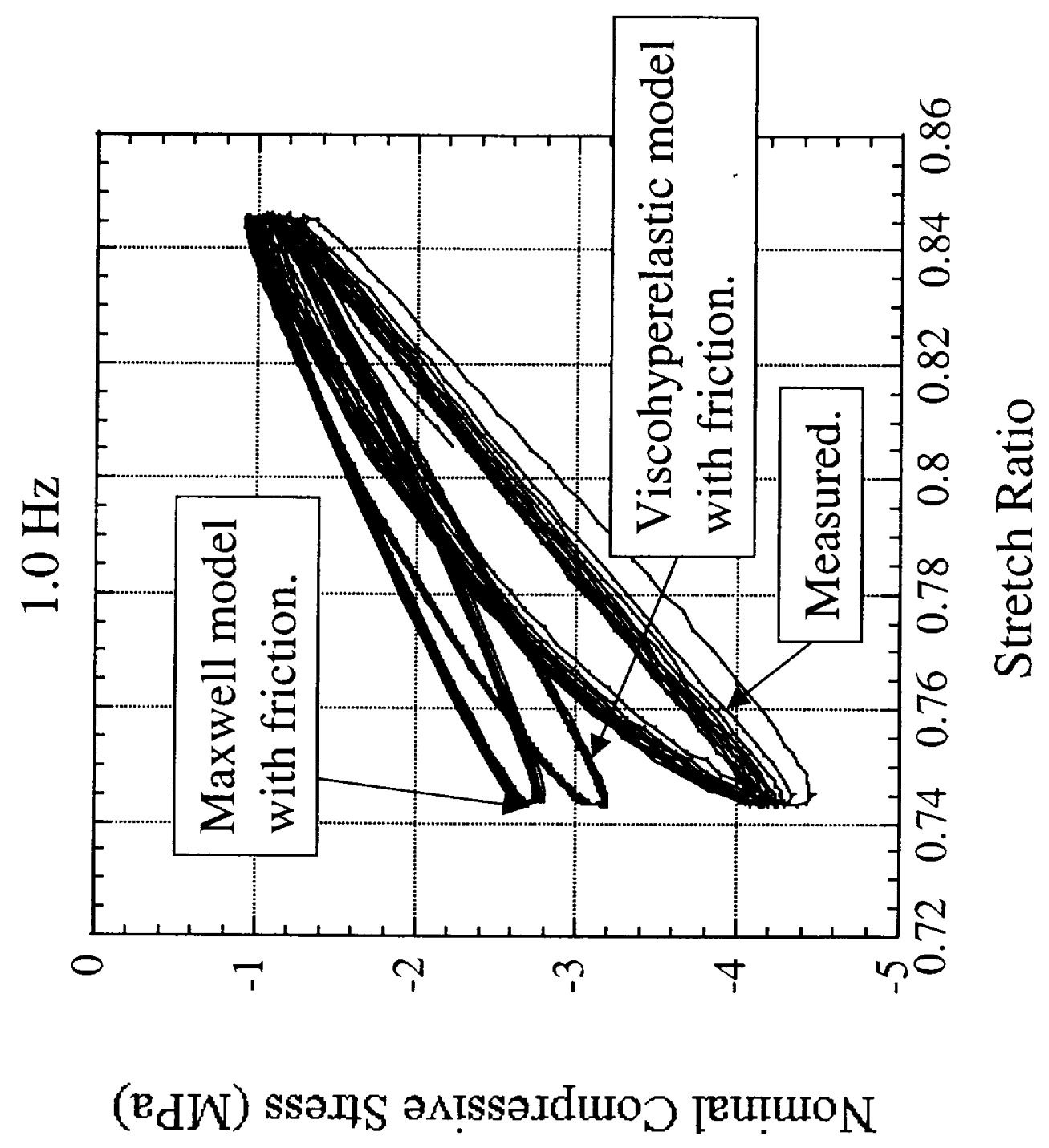




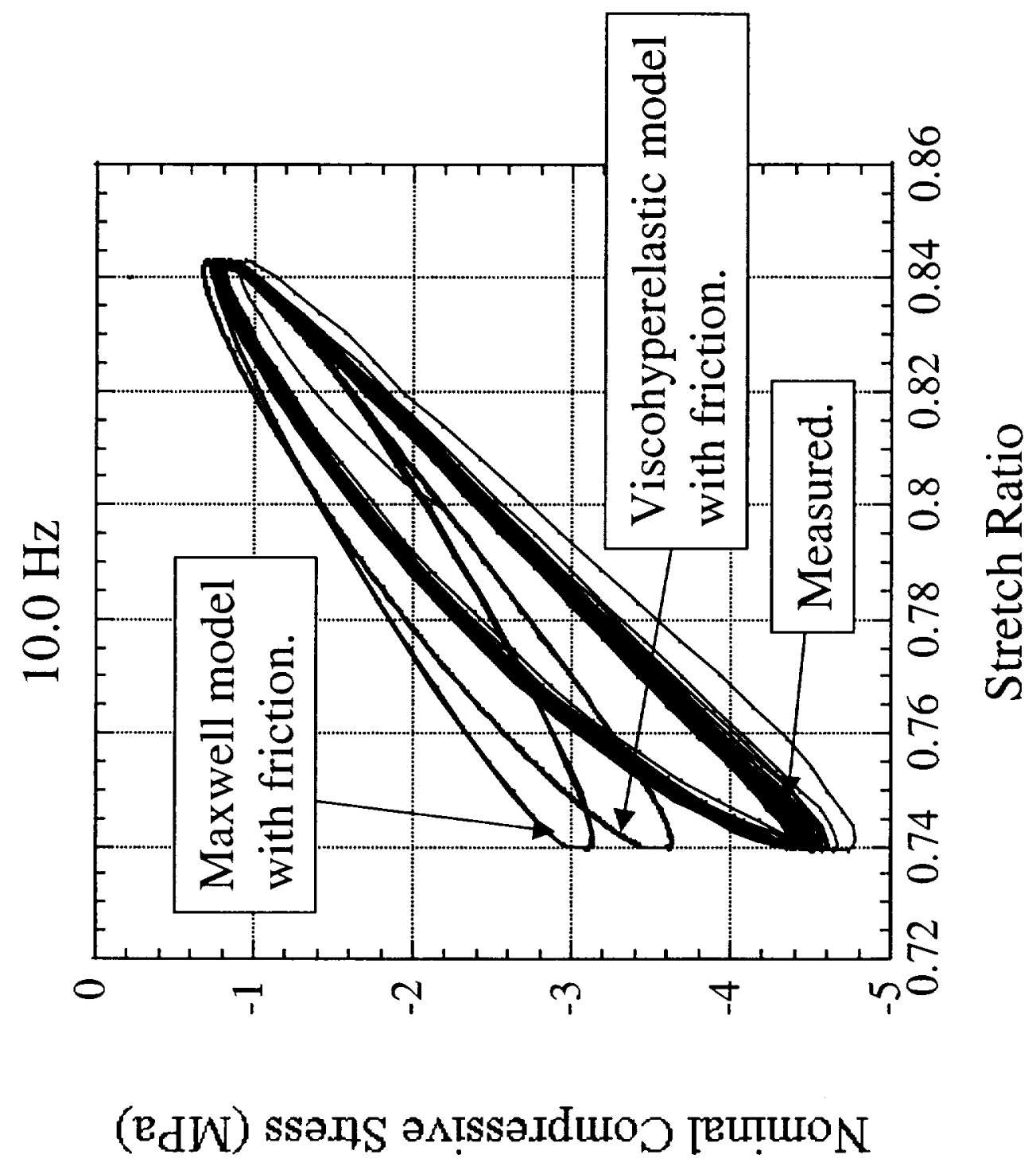

